\title{
Ultrasmall iron particles prepared by use of sodium amalgam
}

\author{
Linderoth, Søren; Mørup, Steen
}

Published in:

Journal of Applied Physics

Link to article, DOI:

10.1063/1.344893

Publication date:

1990

Document Version

Publisher's PDF, also known as Version of record

Link back to DTU Orbit

Citation (APA):

Linderoth, S., \& Mørup, S. (1990). Ultrasmall iron particles prepared by use of sodium amalgam. Journal of Applied Physics, 67(9), 4496-4498. https://doi.org/10.1063/1.344893

\section{General rights}

Copyright and moral rights for the publications made accessible in the public portal are retained by the authors and/or other copyright owners and it is a condition of accessing publications that users recognise and abide by the legal requirements associated with these rights.

- Users may download and print one copy of any publication from the public portal for the purpose of private study or research.

- You may not further distribute the material or use it for any profit-making activity or commercial gain

- You may freely distribute the URL identifying the publication in the public portal

If you believe that this document breaches copyright please contact us providing details, and we will remove access to the work immediately and investigate your claim 


\title{
Ultrasmall iron particles prepared by use of sodium amalgam
}

\author{
S. Linderotin and S. Morup \\ Laboratory of Applied Physics, Technical University of Denmark, DK-2800 Lyngby, Denmark
}

Ultrasmall magnetic particles containing iron have been prepared by reduction of iron ions by the use of sodium in mercury. Mossbauer studies at $12 \mathrm{~K}$ show that the magnetic hyperine field is significantly larger than in bulk $\alpha-\mathrm{Fe}$, suggesting that an iron mercury alloy rather than $\alpha-F e$ has been formed. The particles exhibit superparamagnetic relaxation above $120 \mathrm{~K}$.

\section{INTRODUGTION}

Ferrofluids consisting of transition-metal particles dispersed in a liquid metal have an inherent advantage compared to conventional ferrofiuids because they are excellent heat and electrical conductors. The iron-mercury system is such a system and has been studied extensively in the past. ${ }^{1-3}$ The standard method for preparation of iron-mercury ferrofluids is by electrolysis of iron in aqueous solution with a mercury cathode under vigorous stirring. It has been assumed that microcrystals of $\alpha$-Fe are produced by this method, and magnetization measurements have so far been interpreted with this assumption. However, very recent Mössbauer spectroscopy studies on iron-mercury ferrofluids have revealed magnetic hyperfine fields of $39-40 \mathrm{~T}$ at $12 \mathrm{~K}$ (Refs. 4 and 5), which is significantly larger than the $34.7 \mathrm{~T}$ for single domain $\alpha$-Fe particles.

In this paper we present preliminary Mössbauer spectroscopy studies on an iron-mercury ferrofluid prepared by another method-by reducing the iron ions to the metallic state by sodium amalgam. The results are compared with those for a system prepared by the electrolytic method.

\section{EXPERIBENT}

A sample of sodium amalgam was prepared by dissolving sodium in mercury. The amalgam used in this work contained about $2 \mathrm{wt} . \% \mathrm{Na}$. The sodium amalgam was poured into a beaker on a magnetic stirrer and a solution of $90 \%$ enriched ${ }^{57} \mathrm{Fe}$ metal dissolved in $10 \% \mathrm{H}_{2} \mathrm{SO}_{4}$ was add. ed. The iron ions were reduced to the metallic state through the reaction: $\mathrm{Fe}^{2+}+2 \mathrm{Na} \rightarrow \mathrm{Fe}+2 \mathrm{Na}^{+}$. The process ran for about $1 \mathrm{~h}$. The produced iron amalgam was washed in acetone. A thin film for Mössbauer spectroscopy studies was prepared by squeezing a droplet of the ferrofiuid and freezing it to liquid-nitrogen temperature.

A ferrofluid prepared by the electrolysis method has been studied previousiy. ${ }^{5}$ Some of the results are included in this paper for comparison.

The Mössbauer measurements were carried out with a constant acceleration spectroneter using ${ }^{57} \mathrm{Co}$ in rhodium as the source. Isomer shifts are given relative to $\alpha-\mathrm{Fe}$ at $295 \mathrm{~K}$. Measurements with the sample held at temperatures at or above $80 \mathrm{~K}$ were made with the sample in a liquid nitrogen cryostat. For lower temperatures a closed-cycle helium cryostat was employed. In computer fits the Mössbauer absorption lines were described by Lorentzian lines. A leastsquares method was used for the fitting procedure.

\section{แแ. RESULTS}

In Fig. 1 are shown Mössbauer spectra of the iron-sodium-amalgam obtained at different temperatures in zero applied field.

At $80 \mathrm{~K}$ the spectrum is clearly magnetically split. The spectrum is asymmetric; line 6 is deeper and narrower than line 1 , showing that the spectrum consists of at least two sextets.

At slightly higher temperatures the spectrum collapses and at $120 \mathrm{~K}$ two lines around zero velocity constitute about $50 \%$ of the total area. At $225 \mathrm{~K}$ the Mössbauer spectrum has collapsed completely into two absorption lines positioned at about -0.1 and $0.6 \mathrm{~mm} \mathrm{~s}^{-1}$. The high temperature spectrum resembles that of a ferrofluid produced by the electrolytical method. ${ }^{5}$

When applying an external magnetic field perpendicular to the $\gamma$-ray direction, the magnetic hyperfine splitting at $80 \mathrm{~K}$ increases, and the relative intensities of lines 2 and 5 increases (see Fig. 2). The average magnetic hyperfine field at $80 \mathrm{~K}$, without and with a field of $0.7 \mathrm{~T}$ applied, is deduced to be 31.4 and $33.6 \mathrm{~T}$, respectively.

The Mössbauer spectrum of an iron-sodium-amalgam sample, obtained at about $12 \mathrm{~K}$, is shown in Fig. 3(a). The $12 \mathrm{~K}$ spectrum for an iron-amalgam sample, prepared by electrolysis, is also shown in Fig. 3(b). The two spectra are remarkably similar. The spectra are asymmetric and the lines are broad, showing that at least two magnetically spiit components are present. The average magnetic hyperfine field and the isomer shift are 38-39 $\mathrm{T}$ and about 0.25 $\mathrm{mm} \mathrm{s}^{-1}$, respectively, for both samples.

\section{DISCUSSION}

The collapse of the magnetically split component when increasing the measuring temperature (see Fig. 1) occurs in a manner typical for superparamagnetic particles. This behavior has also previously been observed for an iron-amalgam. ${ }^{5}$ In that case the interpretation was substantiated by 


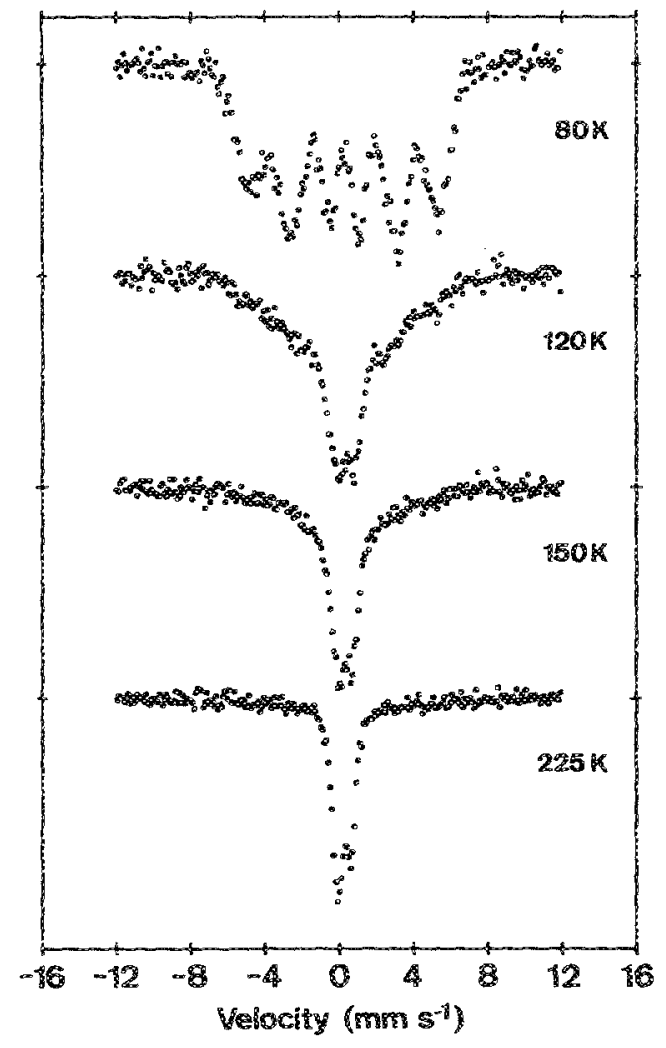

FIG. 1. Mösbauer spectra of the iron-sodium-amalgam obtained at the indicated temperatures in zero applied fie?d.

the application of an external field, which had the effect of restoring the magnetic splitting.

The blocking temperature $T_{B}$ is the temperature below which the Mössbauer spectrum is magnetically split, i.e., the temperature at which the superparamagnetic relaxation time is of the order of $5 \times 10^{-9} \mathrm{~s}$. At temperatures below $T_{B}$ the spectrum is infuenced by collective magnetic excitations, i.e., fluctuations of the direction of magnetization in directions close to the easy direction of magnetization. ${ }^{6}$ These fluctuations lead to a reduction of the magnetic hyperfine splitting in the Mössbauer spectra, which for noninteracting particles with uniaxial anisotropy and with $k T \ll K V$ may be approximated by ${ }^{6,7}$

$$
B_{\text {ubs }} \approx B_{0}(1-k T / 2 K D)
$$

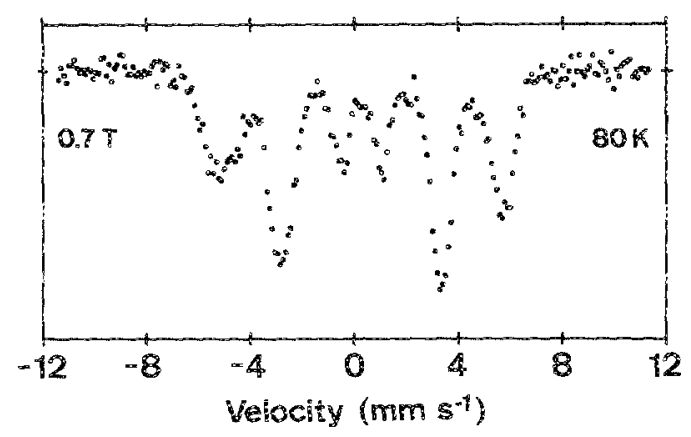

FIG. 2. Mössbauer spectra of the iron-sodium-amalgam, obtained at $80 \mathrm{~K}$, with an external field applied perpendicular to the $\gamma$-ray direction.

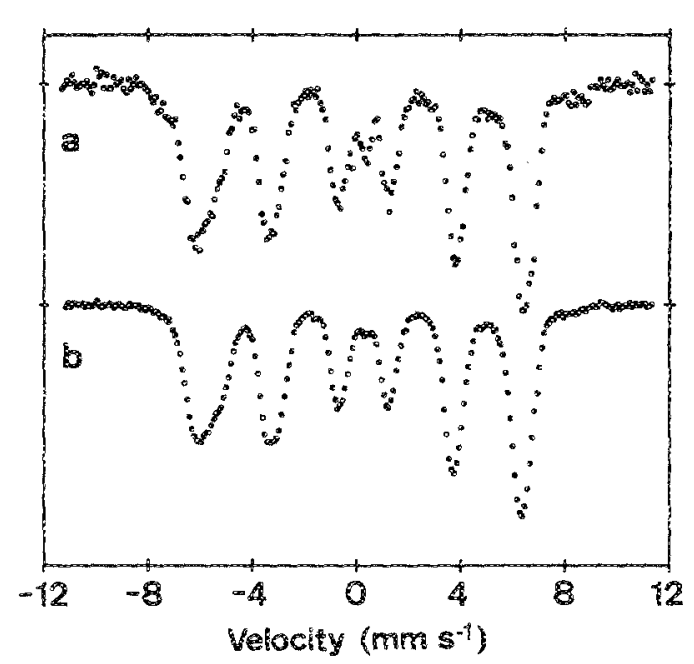

FIG. 3. Mössbauer spectra obtained at $12 \mathrm{~K}$ for (a) the iron-sodium-amalgam system and (b) an iron-nercury system prepared by electrolysis (see Ref. 5).

where $B_{0}$ is the saturation hyperfine field at temperature $T, k$ is Boltzmann's constant, $K$ is the magnetic anisotropy energy constant, and $V$ is the volume of the individual particles.

The collective magnetic excitations can be partiy suppressed by the application of an external field. As the magnetic hyperfine field will be directed opposite an external magnetic field, the true hyperfine field at $80 \mathrm{~K}$, with $0.7 \mathrm{~T}$ applied, is about $34.3 \mathrm{~T}$ for the particles studied here. Taking this value to be $B_{0}$ at $80 \mathrm{~K}$, the product $K V$ can be evaluated to be about $6.5 \times 10^{-21} \mathrm{~J}$.

The superparamagnetic relaxation time of an isolated particle may be expressed by ${ }^{8}$

$$
\tau=\tau_{0} \exp (K V / k T)
$$

where $\tau_{0}$ is in the order of $10^{-10}-10^{-12} \mathrm{~s}$. At $120 \mathrm{~K}$ the relaxation time is about $5 \times 10^{-9}$ from which $K V \approx 7.0 \times 10^{-21} \mathrm{~J}$ is deduced. It is, however, likely that the magnetic interaction between the particles is not negligible. Therefore, the estimated values of $K V$ may be considered as an upper limit. ${ }^{7}$

The temperature dependence of the spectrum is very similar to that found for the sample prepared by electrolysis. ${ }^{5}$ Considering the similarity of the Mössbauer spectra for the two samples produced by the two different methods, the volume, as deduced from a series of field dependence measurements on the sample prepared by electrolysis, ${ }^{5}$ may be taken to be similar, i.e., $V \approx 10^{-25} \mathrm{~m}^{3}$ when the lattice constant is taken to be as for $\alpha$-Fe. If the particles are spherical they are about $6 \mathrm{~nm}$ in diameter.

For spherical $\alpha$-Fe particles with diameters of $6 \mathrm{~mm}$, about $20 \%$ of the iron atoms are at the outer surface layer and their hyperfine parameters will be infuenced by the neighbouring mercury. The second surface layer could also be influenced but it is not likely that the magnetic hyperfine fields at most iron nuclei in a $6 \mathrm{~nm} \alpha$-Fe particle would be considerably larger than for the bulk of single domain $\alpha-\mathrm{Fe}$ particles at $12 \mathrm{~K}(=34.7 \mathrm{~T})$ and it is therefore not likely that the results can be explained solely by surface effects in $\alpha-$ Fe particles. 
Iron and mercury do not form any stable alloys. ${ }^{9}$ The solubility of iron has been estimated to be less than $10^{-5}$ wt. \%. ${ }^{9}$ However, the present Mössbauer results clearly show that the iron is present in a magnetic phase which is different from $\alpha$-Fe. The isomer shift and the magnetic hyperfine field indicate that the iron is in the metallic state, i.e., in an alloy. The similarity of the spectra prepared using sodium amalgam and electrolysis show that the presence of sodium cannot explain the alloy formation in the samples. The results therefore indicate that the iron atoms interact with mercury and probably form a metastable iron-mercury alloy,

\section{CONCLUSIONS}

Mössbauer spectroscopy studies of ferronuids based on iron in mercury have revealed that at $12 \mathrm{~K}$ the magnetic hyperfine fields at the iron atoms are considerably larger than in $\alpha$-Fe. It is proposed that the iron is present in metastable iron-amalgam alloy particles. The particles possess superparamagnetic relaxation with a blocking temperature around $100 \mathrm{~K}$. The Mössbauer spectra of iron amalgams prepared by two quite different methods, i.e., by chemical reduction by sodium and by electrolysis, are remarkably similar.

\section{ACKNOWLEDGMENTS}

The work was supported by the Danish Council for Technical Research and the Danish Council for Natural Sciences.

'F. E. Luborsky, J. Phys. Chem. 61, 1336 (1957),

${ }^{2}$ F. E. Luborsky and P. E. Lawrence, J. Appl. Phys. 32, 231 S (1961).

${ }^{3}$ R. B. Falk and F. E. Luborsky, Trans. Met. Soc. (AlME) 233, 2079 (1965).

${ }^{4} J$. van Wonterghem, S. Morup, S. W. Charles, and S. Wells, J. Magn. Magn. Mater. 65, 276 (1987).

${ }^{5}$ S. Linderoth, S. Mørup, A. Meagher, S. Wells, J. van Wonterghem, H. K. Rasmussen, and S. W. Charles, J. Pinys. (Paris) Collog. C8, 1827 (1988).

${ }^{6} \mathrm{~S}$. Morup, J. A. Dumesic, and H. Topsøe, in Applications of Móssbauer Spectroscopy, edited by R. L. Cohen (Academic, New York, 1980), vol. II, p. 1.

${ }^{7}$ S. Morup, J. Magn. Magn. Mater. 37, 39 (1983).

${ }^{8}$ L. Néel, Ann. Geophys. 5, 99 (1949).

${ }^{9}$ M. Hansen, Consitution of Binary Alloys (McGraw-Hill, New York, 1958). 